\title{
The Upregulation of OCT4 in Acidic Extracellular pH is Associated with Gemcitabine Resistance in Cholangiocarcinoma Cell Lines
}

\author{
Phatchareeporn Choodetwattana ${ }^{1}$, Siriporn Proungvitaya ${ }^{1}$, Patcharee \\ Jearanaikoon ${ }^{1}$, Temduang Limpaiboon ${ }^{2 *}$
}

\begin{abstract}
Background: Cholangiocarcinoma (CCA), although is an uncommon liver cancer originating from bile duct epithelial cells, is one of the top 10 most fatal cancers. Chemoresistance is an unmet need always found in CCA patients. Tumor microenvironment conditions such as hypoxia, nutrient starvation and acidic extracellular $\mathrm{pH}$ play critical roles in chemoresistance and cancer progression. However, the effect of acidic extracellular $\mathrm{pH}$ on cellular response and chemoresistance in CCA has not been studied. Methods: Human CCA cell lines (KKU-M213, KKU-M055 and KKU-100) were cultured under acidic $(\mathrm{pH}$ 6.5) or non-acidic $(\mathrm{pH}$ 7.4) condition and were used for gene expression, doubling time and cytotoxicity assay. Results: The acidic extracellular $\mathrm{pH}(\mathrm{pH}$ 6.5) significantly increased doubling times of CCA cell lines compared with non-acidic condition ( $\mathrm{pH} 7.4)$. Interestingly, extracellular acid condition induced gemcitabine resistance in CCA cell lines. We showed that Octamer-binding transcription factor 4 (Oct4) was upregulated in these cell lines under extracellular acid condition. Conclusion: Our findings demonstrate that CCA cells can adapt to survive in acidic environment after which chemoresistance has been developed. Oct4 may be a key transcriptional regulator which mediates chemoresistance in response to acidic extracellular $\mathrm{pH}$.
\end{abstract}

Keywords: Chemoresistance- tumor microenvironment- octamer-binding transcription factor 4- liver cancer

Asian Pac J Cancer Prev, 20 (9), 2745-2748

\section{Introduction}

Cholangiocarcinoma (CCA) is the most common liver cancer found in Northeast Thailand where the incidence of liver fluke (Opisthorchis viverrini) infection is high. Surgical resection is an effective curative treatment for CCA. Although adjuvant chemotherapy has significantly improved overall survival in CCA patients, the responsiveness is relatively low with a partial response approximately $10-20 \%$ and median overall survival is only 4 months (Bhudhisawasdi et al., 2012; Luvira et al., 2016).

The tumor microenvironment has increasingly appeared as a key player in the development of chemoresistance and tumor progression in the past decade (Yuan et al., 2016; Senthebane et al., 2017). Several studies have demonstrated that the extracellular $\mathrm{pH}$ of solid tumors is acidic (Fukamachi et al., 2010; Zhang et al., 2010; Estrella et al., 2013). Lactic acid produced by anaerobic glycolysis in hypoxic condition seems to be the main cause of acidic extracellular $\mathrm{pH}$, which is an environmental stressor being toxic to many cells, including tumors. Such acidic microenvironment exerts a selective pressure, if tumors have successfully adapted to this condition, they develop more aggressive behavior contributing to chemoresistance and tumor progression (Ibrahim-Hashim and Estrella, 2019). Som et al., (2016) demonstrated that acidic microenvironment in solid tumors induced the expression of octamer-binding transcription factor 4 (Oct4) in fibroblasts and other stromal cells. The Oct4 protein, a transcription factor encoded by the Pou5f1 gene also known as Oct-3, Oct-3/4, Otf3 or NF-A3, belongs to the POU (Pit, Oct, Unc) family of DNA binding-proteins. It binds to the octamer motif ATGCAAAT within the promoter or enhancer regions of target genes to regulate their expression. The expression of Oct4 is associated with pluripotent properties of embryonic stem cells, it is absolutely required for controlling early stages of mammalian embryogenesis (Zeineddin et al., 2014).

However, the effect of acidosis on CCA cell behavior, gene expression and chemotherapeutic response remains unknown. Accordingly, in this study, we aimed to elucidate the behavioral change in CCA cell lines cultured under acidic environment. In this condition, we show that CCA cells slow down cell division, decrease gemcitabine 
sensitivity and upregulate Oct4 gene expression. Our findings indicate that CCA cells enable to survive in acidic environmental stress and this adaptation may have the effect at least in part on chemotherapeutic treatment. The expression of Oct 4 implies some of the stem cell-like phenotypes which may mediate chemoresistance in CCA.

\section{Materials and Methods}

\section{Cell lines and cell culture}

Human CCA cell lines (KKU-M213, KKU-M055 and KKU-100) established in the Cholangiocarcinoma Research Institute, Khon Kaen, Thailand were used in the study (Sripa et al., 2005). Cells were cultured in Ham's F12 Nutrient Mixture (Gibco-BRL, Ontario, Canada) supplemented with $10 \%$ fetal bovine serum and $1 \%$ penicillin/streptomycin (Gibco-BRL) at $37^{\circ} \mathrm{C}$ in a $5 \%$ $\mathrm{CO}_{2}$ atmosphere under acidic $(\mathrm{pH} 6.5)$ or non-acidic $(\mathrm{pH}$ 7.4) condition by which the culture medium was changed every day. Acidic medium was prepared by adding $12 \mathrm{M}$ $\mathrm{HCl}$ to Ham's F-12 until the desired $\mathrm{pH}$ was obtained. After incubation for 5 days, cells were harvested by trypsinization using $0.5 \%$ trypsin-EDTA (Gibco-BRL) and used for gene expression, doubling time and cytotoxicity assay.

\section{$R N A$ isolation and reverse transcription-polymerase chain reaction ( $R T-P C R)$}

Total RNA was isolated from all cell lines using TRIzol ${ }^{\circledR}$ reagent (Invitrogen, Carlsbad, CA, USA). The cDNA was synthesized by reverse transcription of total RNA using ImProm-II ${ }^{\mathrm{TM}}$ Reverse Transcription System (Promega Corporation, Madison, WI, USA) according to the manufacturer's protocols. The primer sequences were as follows; Oct4a: forward 5'-GGTTGAGTAGTCCCTTCGCAAGC-3'; reverse 5'-CTTAGCCAGGTCCGAGGATCAAC-3' and glyceraldehyde 3-phosphate dehydrogenase (GAPDH): forward 5'-ATGTTCGTCATGGGTGTGAA-3'; reverse 5'-AGAGGCAGgGatgatgTtCT-3'. The PCR reaction was carried out using a Rotor-Gene Q (Qiagen, South San Francisco, CA, USA). The $50 \mu \mathrm{L}$ of PCR reaction consisted of $1 \mathrm{x}$ PCR buffer $(67 \mathrm{mM}$ Tris, $\mathrm{pH}$ 8.4, $16.6 \mathrm{mM}$ ammonium sulfate and $0.1 \%$ Tween-20), $0.2 \mu \mathrm{M}$ of each primer, $200 \mu \mathrm{M}$ of each dNTP, $50 \mathrm{ng}$ of cDNA, $1.5 \mu \mathrm{M} \mathrm{SYTO}^{\circledR} 9$ (Invitrogen), $2 \mathrm{mM} \mathrm{MgCl}_{2}$ and 5 units of Taq DNA polymerase. The cycling stage was performed as following steps: initial denaturation at $90^{\circ} \mathrm{C}$ for $10 \mathrm{~min}, 40$ cycles of denaturation at $90^{\circ} \mathrm{C}$ for $20 \mathrm{sec}$, and annealing and extension at $62^{\circ} \mathrm{C}$ for $20 \mathrm{sec}$. Relative gene expression was analyzed by the comparative $\mathrm{Ct}$ method $\left(2^{-\Delta \Delta C t}\right)$.

\section{Doubling time assay}

The doubling time of CCA cell lines was performed using Sulforhodamine B (SRB) assay. Briefly, cells were fixed with $10 \%(\mathrm{~W} / \mathrm{V})$ trichloroacetic acid, stained with SRB for $30 \mathrm{~min}$, and washed repeatedly with $1 \%(\mathrm{~V} / \mathrm{V})$ acetic acid to remove excess dye. The protein-bound dye was dissolved in $10 \mathrm{mM}$ Tris base solution and determined for the absorbance at $510 \mathrm{~nm}$ using a microplate reader
(Tecan Ltd., Reading, UK). The doubling time was determined using an on-line calculator (http://www. doubling-time.com/compute.php).

\section{Cytotoxicity assay}

Cells with density of $2 \times 10^{3}$ were seeded in triplicate in a flat-bottom 96-well plate and allowed to grow for $24 \mathrm{~h}$. Then, $100 \mu \mathrm{L}$ of medium containing different concentrations of gemcitabine were added to each well to get a final concentration of 10, 20, 40, 80, 160 and $320 \mathrm{nM}$, respectively. After $72 \mathrm{~h}$, cell viability was performed using $\mathrm{SRB}$ assay. The percentage of cell viability was calculated using the following formula: (mean ODsample)/ (mean ODday0) x 100.

\section{Statistical analysis}

All experiments were performed independently three times. The data were expressed as mean \pm standard deviation (SD) and analyzed using SPSS 17.0 software (SPSS Inc., Chicago, IL, USA). The differences in doubling time, cell viability and relative gene expression between acidic and non-acidic condition were analyzed using Student's t-test. $\mathrm{P} \leq 0.05$ was considered statistically significant.

\section{Results}

Cells cultured in acidic extracellular $\mathrm{pH}$ showed longer doubling time

The population doubling time of KKU-M213, KKU-M055 and KKU-100 was determined after being cultured for 5 days under acidic (pH 6.5) and non-acidic (pH 7.4) conditions. It was found that acidic extracellular $\mathrm{pH}$ significantly increased doubling time in all CCA cell lines when compared to cell grown in $\mathrm{pH} 7.4$ (Figure 1 ), indicating the reduction of cell growth in acidic environment.

\section{Acidic extracellular $\mathrm{pH}$ caused gemcitabine resistance} in CCA cell lines

After culture for 5 days under acidic ( $\mathrm{pH}$ 6.5) and non-acidic (pH 7.4) conditions, cells were treated with different concentrations of gemcitabine for $72 \mathrm{~h}$ and determined for cell viability. We found that cells grown in $\mathrm{pH} 6.5$ remained viable and resistant to gemcitabine even at high concentration $(320 \mathrm{nM})$ while cells cultured in $\mathrm{pH}$ 7.4 were killed and sensitive to gemcitabine (Figure 2). Our finding suggested that acidic extracellular $\mathrm{pH}$ had an effect on gemcitabine resistance in CCA cell lines.

Acidic extracellular $p H$ induced the upregulation of Oct4

It has been reported that acidic extracellular $\mathrm{pH}$ could induce the expression of Oct4 in fibroblast and stromal cells in tumor models (Som et al., 2016). Our study showed that Oct4 was significantly highly upregulated in CCA grown in acidic $\mathrm{pH}$ when compared to those cultured in non-acidic condition (Figure 3).

\section{Discussion}

Tumor microenvironment such as hypoxia, nutrient 


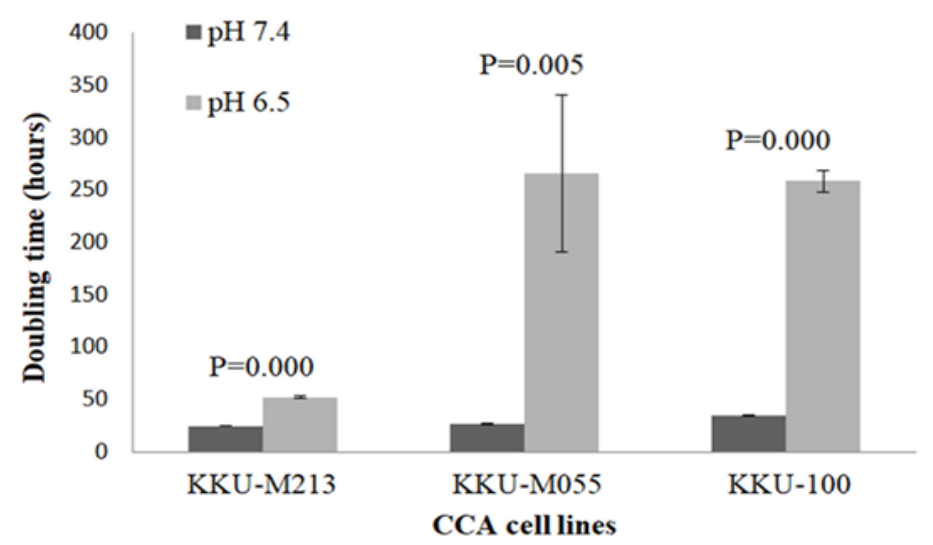

Figure 1. The Population Doubling Time of CCA Cell Lines under Non-Acidic (pH 7.4) and Acidic (pH 6.5) Conditions.
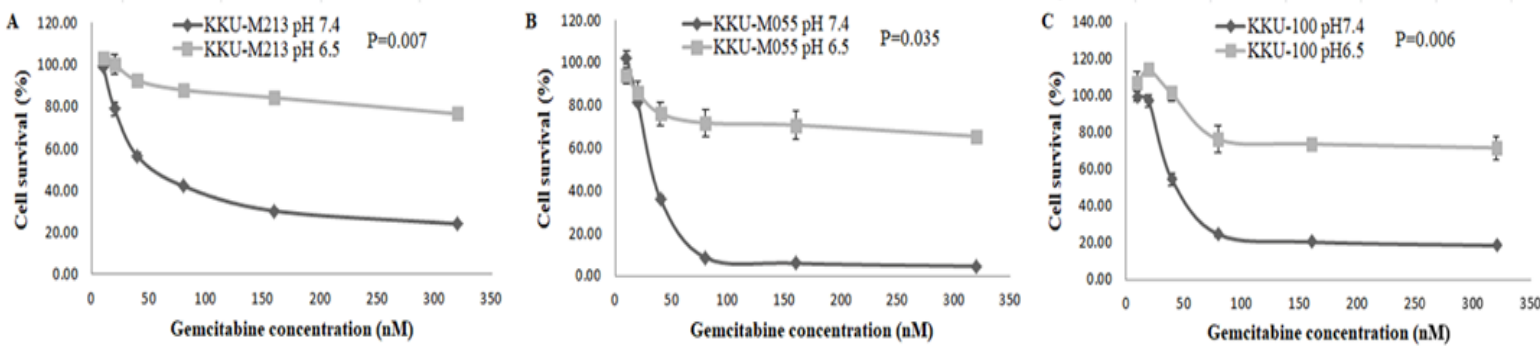

Figure 2. Effects of Gemcitabine on Cell Survival. CCA cell lines were treated with various concentrations of gemcitabine for $72 \mathrm{~h}$ then cell viability was performed using SRB assay. (A) KKU-M213, (B) KKU-M055, (C) KKU-100.

starvation and acidic extracellular $\mathrm{pH}$ play critical roles in tumor growth, invasion and metastasis, as well as anti-cancer drug resistance (Estrella et al., 2013; Ibrahim-Hashim and Estrella, 2019). The extracellular $\mathrm{pH}$ of tumor tissues is often acidic, which lactic acid produced by anaerobic and aerobic glycolysis (Warburg effect) is the major cause and $\mathrm{CO}_{2}$ production via the pentose phosphate pathway is an alternative cause of acidic microenvironment (Helmlinger et al., 2002; Vander Heiden et al., 2009). The extracellular $\mathrm{pH}$ of solid tumors becomes acidic with the $\mathrm{pH}$ range of 6.4-6.9 (Gerweck and Seetharaman, 1996). Many lines of evidence indicate the important effect of acidic microenvironment on both cancer and stromal cells as well as their behavior (Kato et al., 2013; Som et al., 2016). We have shown that all CCA cell lines cultured under acidic $\mathrm{pH}$ had significantly longer doubling time than those grown in non-acidic condition. Our study was consistent with the study of Kondo et al., (2017), which performed the effect of low $\mathrm{pH}$, hypoxia and nutrient starvation culture conditions on cell growth and adhesion of PANC-1 and AsPC-1 pancreatic cancer cells. They showed that acidic extracellular $\mathrm{pH}(\mathrm{pH}$ 6.8) significantly reduced cell growth and adhesion of PANC-1 and AsPC-1 compared with control ( $\mathrm{pH}$ 7.4). Moreover, acidic $\mathrm{pH}$ decreased cell growth compared with hypoxia and nutrient starvation in PANC-1 and AsPC-1 suggesting that acidic $\mathrm{pH}$ triggered different cellular responses from hypoxia and nutrient starvation.

Adjuvant therapy such as chemotherapy and radiotherapy is given to the patients after surgery to

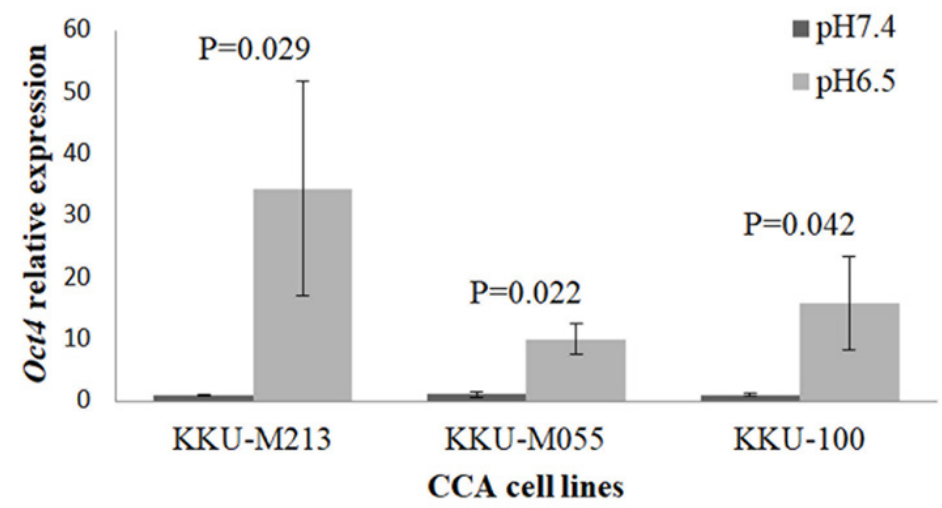

Figure 3. Relative mRNA Expression of Oct4 in CCA Cell Lines 
prevent recurrence of the disease. Chemoresistance is an unmet need which causes recurrence, dissemination and death in cancer patients. The molecular mechanisms of chemoresistance include transporter pumps, oncogenes, tumor suppressor gene, mitochondrial alteration, DNA repair, autophagy, epithelial-mesenchymal transition (EMT), cancer stemness, and exosome (Zheng, 2017). Moreover, the $\mathrm{pH}$ in the tumor microenvironment can affect the cytotoxicity of anti-cancer drugs. Anti-cancer drugs mainly target the rapidly proliferating cancer cells. Therefore, slow-growing cells have a trend to develop chemoresistance. This study demonstrated the high percentage of cell viability in the presence of gemcitabine under acidic condition. Our findings indicate the low efficiency of gemcitabine even at high concentration, which cannot kill slowly dividing cancer cells under acidic microenvironment resulting in chemoresistance. It has been shown that lactic acid can also contribute to tumor radioresistance, due to its antioxidant properties (Sattler et al., 2010).

Our study revealed that Oct4 was upregulated in response to acidic extracellular $\mathrm{pH}$, which was different from the study of Kondo et al., (2017). They showed that extracellular acidity activates the upregulation of sterol regulatory element-binding protein-2 (SREBP2), a transcriptional regulator of cholesterol biosynthetic enzymes, by which acyl-CoA synthetase short-chain family member 2 (ACSS2), a direct SREBP2 target, promotes tumor growth and progression in pancreatic cell lines. They also showed that transcriptional regulators identified under hypoxia are hypoxia-inducible factor 1A (HIF1A) and HIF2A, and under nutrient starvation are activating transcription factor 4 (ATF4) and forkhead box $\mathrm{O} 3$ (FOXO3). In this study, acidic extracellular $\mathrm{pH}$ could facilitate cellular reprogramming, as indicated by increased Oct 4 expression. The expression of Oct 4 implies some of the stem cell-like phenotypes which may mediate chemoresistance in CCA. Therefore, the use of anti-Oct4 as a targeted therapy may be an innovative regime for effective treatment of CCA.

In summary, we demonstrate the effect of acidic extracellular $\mathrm{pH}$ on cellular behavior of CCA cell lines including reduction of cell growth, increase of gemcitabine resistance and upregulation of Oct4. Our findings may shed light on the important role of tumor microenvironment, in particular acidic extracellular $\mathrm{pH}$, on the development of chemoresistance in CCA, in which the manipulation of Oct4 must be scrutinized for treatment efficacy.

\section{Acknowledgements}

This work was financially supported by the Thailand Research Fund through the Royal Golden Jubilee Ph.D. Program and Khon Kaen University (grant no. PHD/0072/2554 to P. Choodetwattana), and Khon Kaen University Research Affairs under the National Research Council of Thailand (grant no. 600904). We appreciated the Cholangiocarcinoma Research Institute, Khon Kaen University, Khon Kaen, Thailand for kindly providing CCA cell lines.

\section{References}

Bhudhisawasdi V, Talabnin C, Pugkhem A, et al (2012). Evaluation of postoperative adjuvant chemotherapy for intrahepatic cholangiocarcinoma patients undergoing R1 and R2 resections. Asian Pac J Cancer Prev, 13, 169-74.

Estrella V, Chen T, Lloyd M, et al (2013). Acidity generated by the tumor microenvironment drives local invasion. Cancer Res, 73, 1524-35.

Fukamachi T, Chiba Y, Wang X, et al (2010). Tumor specific low $\mathrm{pH}$ environments enhance the cytotoxicity of lovastatin and cantharidin. Cancer Lett, 297, 182-9.

Gerweck LE, Seetharaman K (1996). Cellular pH gradient in tumor versus normal tissue: potential exploitation for the treatment of cancer. Cancer Res, 56, 1194-8.

Helmlinger G, Sckell A, Dellian M, Forbes NS, Jain RK (2002). Acid production in glycolysis-impaired tumors provides new insights into tumor metabolism. Clin Cancer Res, $\mathbf{8}$, 1284-91.

Ibrahim-Hashim A, Estrella V (2019). Acidosis and cancer: from mechanism to neutralization. Cancer Metastasis Rev, 38, 149-55.

Kato Y, Ozawa S, Miyamoto C, et al (2013). Acidic extracellular microenvironment and cancer. Cancer Cell Int, 13, 89.

Kondo A, Yamamoto S, Nakaki R, et al (2017). Extracellular acidic $\mathrm{pH}$ activates the sterol regulatory element-binding protein 2 to promote tumor progression. Cell Rep, 18, $2228-42$.

Luvira V, Nilprapha K, Bhudhisawasdi V, et al (2016). Cholangiocarcinoma patient outcome in Northeastern Thailand: Single-center prospective study. Asian Pac J Cancer Prev, 17, 401-6.

Sattler UGA, Meyer SS, Quennet V, et al (2010). Glycolytic metabolism and tumour response to fractionated irradiation. Radiother Oncol, 94, 102-9.

Senthebane DA, Rowe A, Thomford NE, et al (2017). The Role of tumor microenvironment in chemoresistance: To survive, keep your enemies closer. Int J Mol Sci, 18, 1586.

Som A, Bloch S, Ippolito JE, Achilefu S (2016). Acidic extracellular $\mathrm{pH}$ of tumors induces octamer-binding transcription factor 4 expression in murine fibroblasts in vitro and in vivo. Sci Rep, 6, 27803.

Sripa B, Leungwattanawanit S, Nitta T, et al (2005). Establishment and characterization of an opisthorchiasisassociated cholangiocarcinoma cell line (KKU-100). World J Gastroenterol, 11, 3392-7.

Vander Heiden MG, Cantley LC, Thompson CB (2009). Understanding the Warburg effect: The metabolic requirements of cell proliferation. Science, 324, 1029-33.

Yuan Y, Jiang YC, Sun CK, Chen QM (2016). Role of the tumor microenvironment in tumor progression and the clinical applications (Review). Oncol Rep, 35, 2499-515.

Zeineddine D, Hammoud AA, Mortada M, Boeuf H (2014). The Oct4 protein: more than a magic stemness marker. $\mathrm{Am}$ J Stem Cells, 3, 74-82.

Zhang X, Lin Y, Gillies RJ (2010). Tumor pH and its measurement. J Nucl Med, 51, 1167-70.

Zheng HC (2017). The molecular mechanisms of chemoresistance in cancers. Oncotarget, 8, 59950-64.

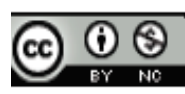

This work is licensed under a Creative Commons AttributionNon Commercial 4.0 International License. 